\title{
Punch Stretch Test for TRIP690 and DP780 Steel at Elevated Temperatures
}

\author{
Robert Krupa ${ }^{1, a^{*}}$ \\ ${ }^{1}$ Kirchhoff Poland, ul. Wojska Polskiego 3, 39-300 Mielec, Poland \\ arobert.krupa@kirchhoff-automotive.com
} Keywords: Warm sheet metal forming, retained austenite stability, TRIP effect, temper
embrittlement

\begin{abstract}
The forming at elevated temperatures for Advanced High Strength Steels (AHSS) opens up a new technology. The phase changes during warm deformation are the key to understanding the warm forming process. The desired microstructure and mechanical properties before and after warm forming have to be known in order to find optimal conditions for achieving good sheet formability and preferred material properties in service. In this work, the TRIP690 and DP780 steels are investigated under punch stretch test conditions in order to evaluate the temperature influence on neck formation and fracture occurrence at ambient and elevated temperatures $200{ }^{\circ} \mathrm{C}, 400{ }^{\circ} \mathrm{C}$. Contact heat treatment was used for heating up the circular specimens. It was found that formability of the investigated steels was drastically reduced at a temperature of $400{ }^{\circ} \mathrm{C}$ and brittle fracture occurred because of temper embrittlement. It is recommended to avoid steel tempering at this critical temperature.
\end{abstract}

\section{Introduction}

The most basic paradigm of material science is that an increase in strength leads to a loss of ductility and an increase in ductility can be achieved through loss in strength. Both high strength and good formability are required for automotive sheet materials in order to allow thinner sheet thickness, which reduces weight and increases fuel efficiency. Formability is necessary for stamping the complex parts without necking and fracture. Many materials have been developed by steel makers in order to find a balance between strength and ductility.

Due to the complexity of the mechanism which produces TRIP effect (Transformation Induced Plasticity), the formability of the industrial parts is still a challenging issue considering factors such as temperature, stress state, strain path, strain rate or even heating induced by deformation. The dependence of the mechanical behavior of TRIP steel on temperature and deformation rate is still not completely understood.

The major drawback of metastable materials with retained austenite and martensite is unpredictable mechanical properties during and after forming. The influence of strain rate, plastic deformation and temperature on the transformation kinetics of TRIP steel and Dual Phase steel has been analyzed by many researchers. From these works several conclusions can be drawn [1]:

- Plastic deformation triggers the martensitic transformation. It provides the driving force, (corresponding to the difference in the free energy between austenite and martensite) necessary to initiate and achieve the transformation,

- Martensitic transformation is strongly dependent on the initial temperature. The driving force required to induce the transformation varies with the temperature. For temperatures under a certain level $\mathrm{M}_{\mathrm{s}}$, the transformation may be reached in the absence of plastic deformation. For temperatures above a critical value $\mathrm{M}_{\mathrm{f}}$, martensite will not be formed, no matter how much the austenite is deformed,

- Due to the relation existing between deformation and temperature in the material behavior, the strain rate also plays a crucial role in the phase transformation process. 
To apply the warm forming to TRIP and dual phase steel the tempering process should be considered where material is heated and formed at elevated temperatures and then cooled in the air to room temperature. Temper embrittlement called sometimes blue embrittlement (due to a blue color on steel surface) results in a loss of ductility and fracture resistance and usually occurs after tempering at a temperature range of $250-400^{\circ} \mathrm{C}$.

During tempering a number of metallurgical effects take place. Already at temperatures in the range of $150-200^{\circ} \mathrm{C}$ effects are noticeable [2]. Medium carbon steels $(\mathrm{C}>0.2 \%)$ show strength decrease as precipitation of $\varepsilon$ - carbides occurs. Low carbon steels $(\mathrm{C}<0.2 \%)$ are less sensitive with regard to strength loss. Tempering at temperatures above $200^{\circ} \mathrm{C}$ leads to a further rapid decrease in strength. Precipitation of needle shaped cementite causes additionally a loss of elongation and toughness [3]. The Effect is known as one-step temper embrittlement [4]. Tempering of martensitic steel for crash relevant automotive components should be avoided. On the other hand, a typical paint-baking treatment $\left(180^{\circ} \mathrm{C} / 20\right.$ minutes $)$ is not critical regarding the property profile required for good crash performance [5].

The investigation into the mechanisms of tempered martensite embrittlement is also presented in paper [6] with particular focus given to the role of interlath films of retained austenite in commercial, ultra-high strength AISI 4340 (1.6565 40NiCrMo6) alloy steel. The embrittlement was found to be concurrent with the interlath precipitation of cementite during tempering and the consequent mechanical instability of interlath films of retained austenite during subsequent loading. The magnitude of the embrittlement was found to be significantly greater in microstructures containing increasing volume fractions of retained austenite. A complete mechanism of tempered martensite embrittlement is proposed involving precipitation of interlath cementite due to partial thermal decomposition of interlath films of retained austenite and subsequent deformation - induced transformation on loading of remaining interlath austenite, destabilized by carbon depletion from carbide precipitation. The deterioration in toughness, associated with temper embrittlement is therefore ascribed to embrittling effect of interlath cementite precipitates and an interlath layer of mechanically - transformed austenite, i.e., untempered martensite. The presence of residual impurity elements in prior austenite grain boundaries, having segregated there during austenitization, may accentuate this process by providing an alternative weak path for fracture.

The intensity of microcracks and brittle fracture of martensitic steel MS-W 900Y1180T is also reported in paper [7], for blank temperature $310^{\circ} \mathrm{C}$ and $420^{\circ} \mathrm{C}$ and sheet forming temperature $200{ }^{\circ} \mathrm{C}$ and $250{ }^{\circ} \mathrm{C}$ respectively, as shown in Fig. 1. There were no microcracks after forming at ambient temperature.

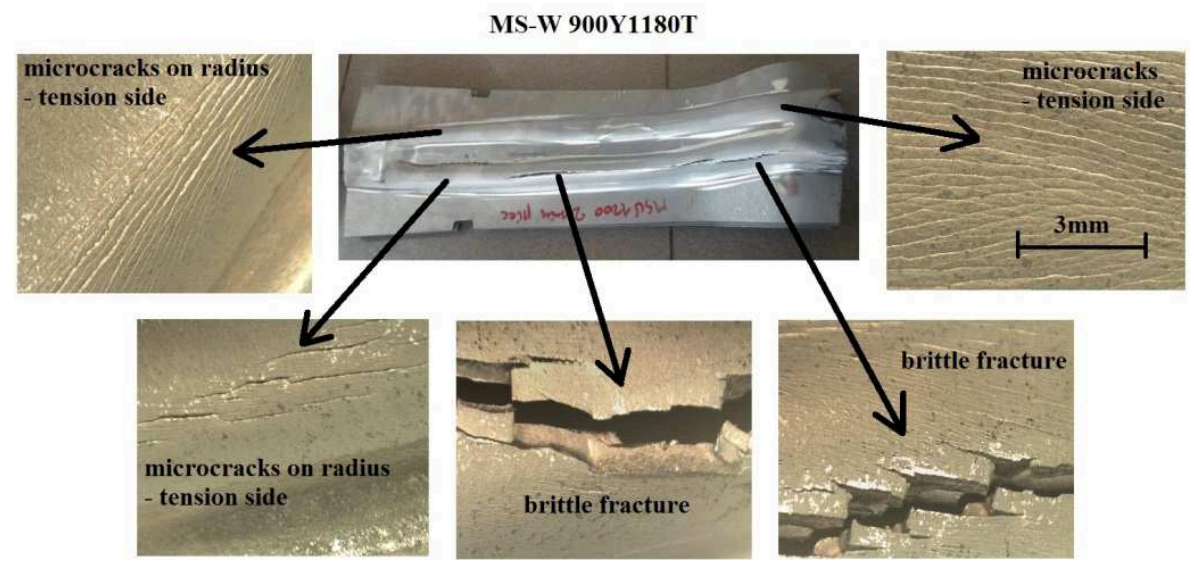

Fig. 1. Intensity of microcracks on tensile side of bending and brittle fracture of martensitic steel for peak blank temperature $420^{\circ} \mathrm{C}$ and forming temperature $250{ }^{\circ} \mathrm{C}[7]$ 


\section{Experimental Research}

In order to find the relation between elevated temperatures, neck occurrence and the temper embrittlement the punch stretch test was carried out on the circular specimens ( $1.5 \mathrm{~mm}$ thick) with a diameter of $100 \mathrm{~mm}$. The hemispherical punch $(50 \mathrm{~mm})$ was used for stretch forming. The experimental equipment is shown in Fig. 2. The process of contact heat was used for specimen heating [8]. The heat treatment of a blank takes place between two heating plates. These plates are heated to the desired temperature and this temperature is kept constant, $200{ }^{\circ} \mathrm{C}$ or $400{ }^{\circ} \mathrm{C}$ respectively. The heat transfer takes place as a cold blank is positioned between the plates and they are brought in contact. The heated plates guarantee rapid heating of steel sheets. The holding time of the specimen between two heating plates was $15 \mathrm{~s}$. After this time the specimen was quickly placed on the tool to conduct the punch stretch test. The experimental tool consists of a heated die and blank holder. The drawbeads were not used in the tool because the blank holder force $(400 \mathrm{kN})$ guarantied material stretch condition. The punch was not heated- it was only pre-heated to a temperature of approx. 50 or $100{ }^{\circ} \mathrm{C}$ respectively (after 5 trials/press strokes) because of heat transfer from specimen to the punch. It can be assumed that the forming process is almost isothermal because there was not sufficient time during forming for heat transfer between punch and blank (formed part). The temperature of the specimen was monitored by thermo camera. After the press stroke the formed part was cooled in the air to room temperature.
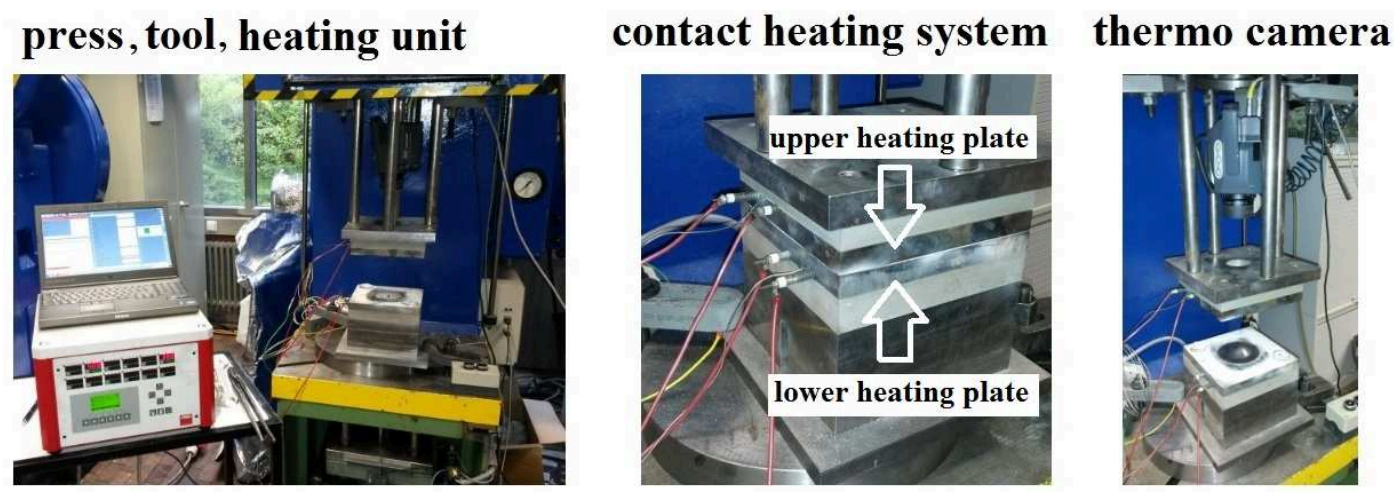

Fig. 2. Experimental equipment for punch stretch test at elevated temperatures

Minimum 5 trials were conducted for each condition in order to be sure that the results are repeatable. Fig. 3 shows achieved results from the punch stretch test at ambient and elevated temperatures. It can be seen that the blue color appeared on the steel surface at temperature $400{ }^{\circ} \mathrm{C}$ and temper embrittlement (brittle fracture) occurred for TRIP and DP steel. It is clearly observed that the neck formation occurred for TRIP steel at temperature $200{ }^{\circ} \mathrm{C}$ but no visible necking for DP780 steel- only uniform strain distribution (thinning).

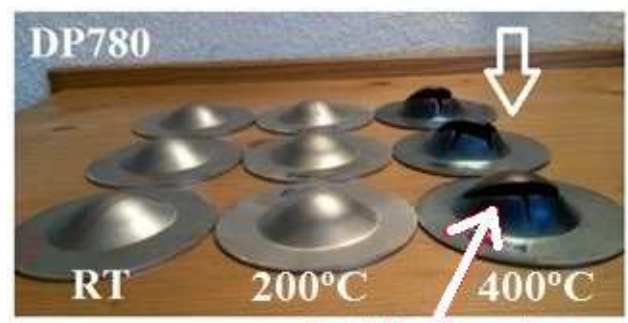

brittle fracture

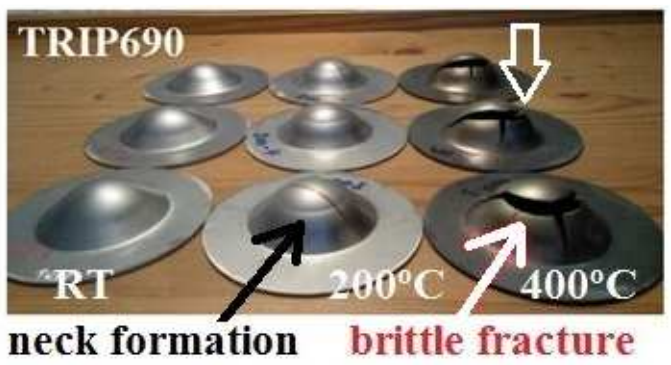

neck formation brittle fracture

Fig. 3. Results from punch stretch test at ambient and elevated temperature $200{ }^{\circ} \mathrm{C}$ and $400{ }^{\circ} \mathrm{C}$

The test was conducted on the hydraulic press. The punch displacement into material (dome height) is presented in Table 1 . The punch achieved boundary/limiting position $(20 \mathrm{~mm})$ only for specimen temperature $400{ }^{\circ} \mathrm{C}$. In other cases the material resistance allowed to obtain smaller punch 
penetration. The necking occurred for approximate punch displacement $18.1 \mathrm{~mm}$ for TRIP steel at $200{ }^{\circ} \mathrm{C}$ - the retained austenite is more stable, the TRIP effect is suppressed and the material is not able to withstand the neck formation. The difference for punch displacement for both evaluated steels at $200{ }^{\circ} \mathrm{C}$ is almost $1 \mathrm{~mm}$ but the difference in neck delay is meaningful - this disadvantage makes TRIP steel less useful for deep drawn parts in comparison to cold forming condition.

Table 1. Punch displacement into material for different test temperature

\begin{tabular}{|c|c|c|c|}
\hline & RT & $200^{\circ} \mathrm{C}$ & $400^{\circ} \mathrm{C}$ \\
\hline DP780 & $\mathbf{1 5 . 2}[\mathrm{mm}]$ & $\mathbf{1 7 . 2}[\mathrm{mm}]$ & $\mathbf{2 0}[\mathrm{mm}]$ \\
\hline TRIP690 & $\mathbf{1 6 . 0}[\mathrm{mm}]$ & $\mathbf{1 8 . 1}[\mathrm{mm}]$ & $\mathbf{2 0}[\mathrm{mm}]$ \\
\hline
\end{tabular}

The microhardness HV10 (Vickers) was measured to see influence of temperature on microstructural changes in comparison to cold forming. The specimens were cut and prepared for measuring as presented in Fig.4. The distance between measurement points was chosen $1.5 \mathrm{~mm}$ following from the left to the right side of the section. As shown in Fig. 5, the material hardness increased progressively after deformation. The hardness increase is observed also locally in the area of die radius (additional bending deformation) and close to neck formation, especially for TRIP steel. The hardness change is also visible for material without deformation in the unstressed microstructure (points from 1 to 12) - the material didn't flow between blankholder and die (stretch condition) - the hardness change is caused only by temperature influence (tempering). It is also recognized that the hardness for TRIP steel is locally more unstable than for DP steel, it means that the metastable austenite is sensitive for process parameters and deformation condition.

Figure 5 presents also tensile strength (estimated values) related to hardness (HV) according to conversion recommended in standard ISO 18265: 2003. It is seen that there is strength variation for DP and TRIP materials at elevated temperature in comparison to cold forming. This remark should be carefully considered in potential analysis for warm forming process.
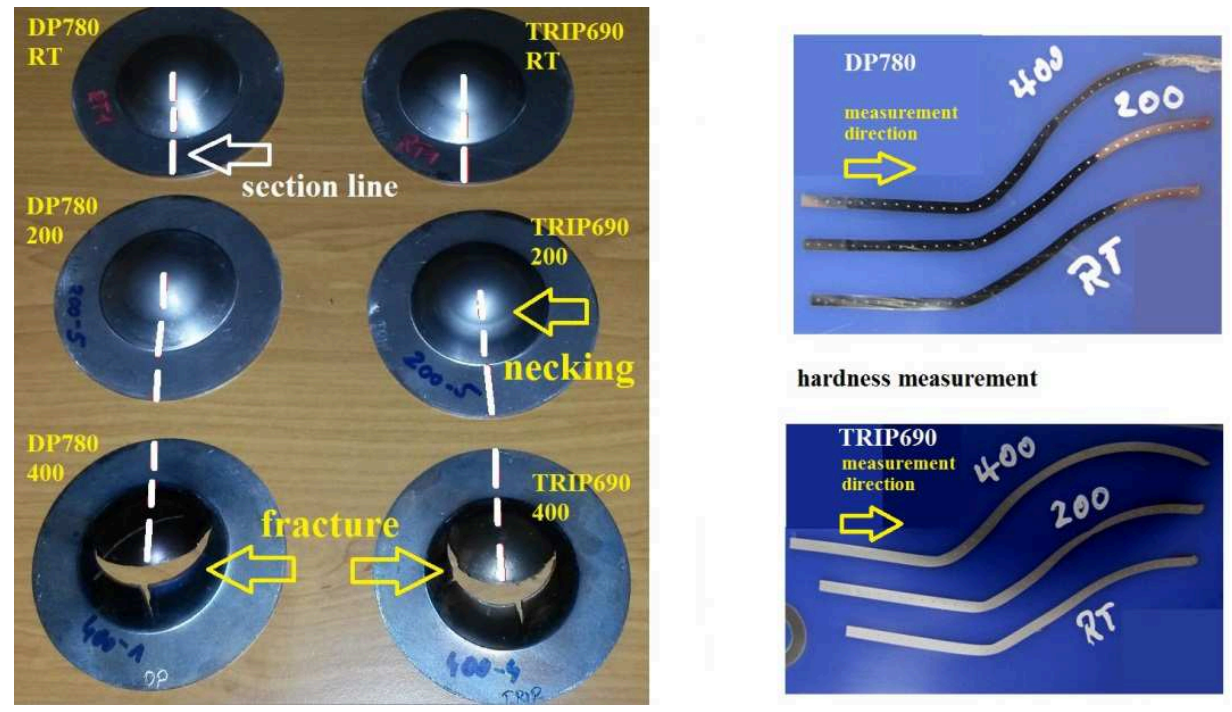

hardness measurement

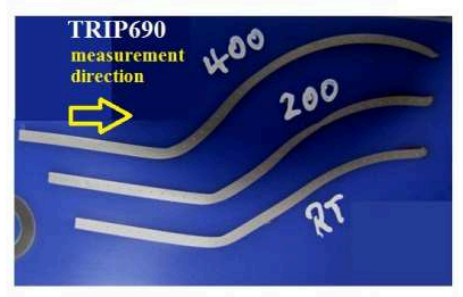

Fig. 4. Specimen preparation for microhardness measurement 

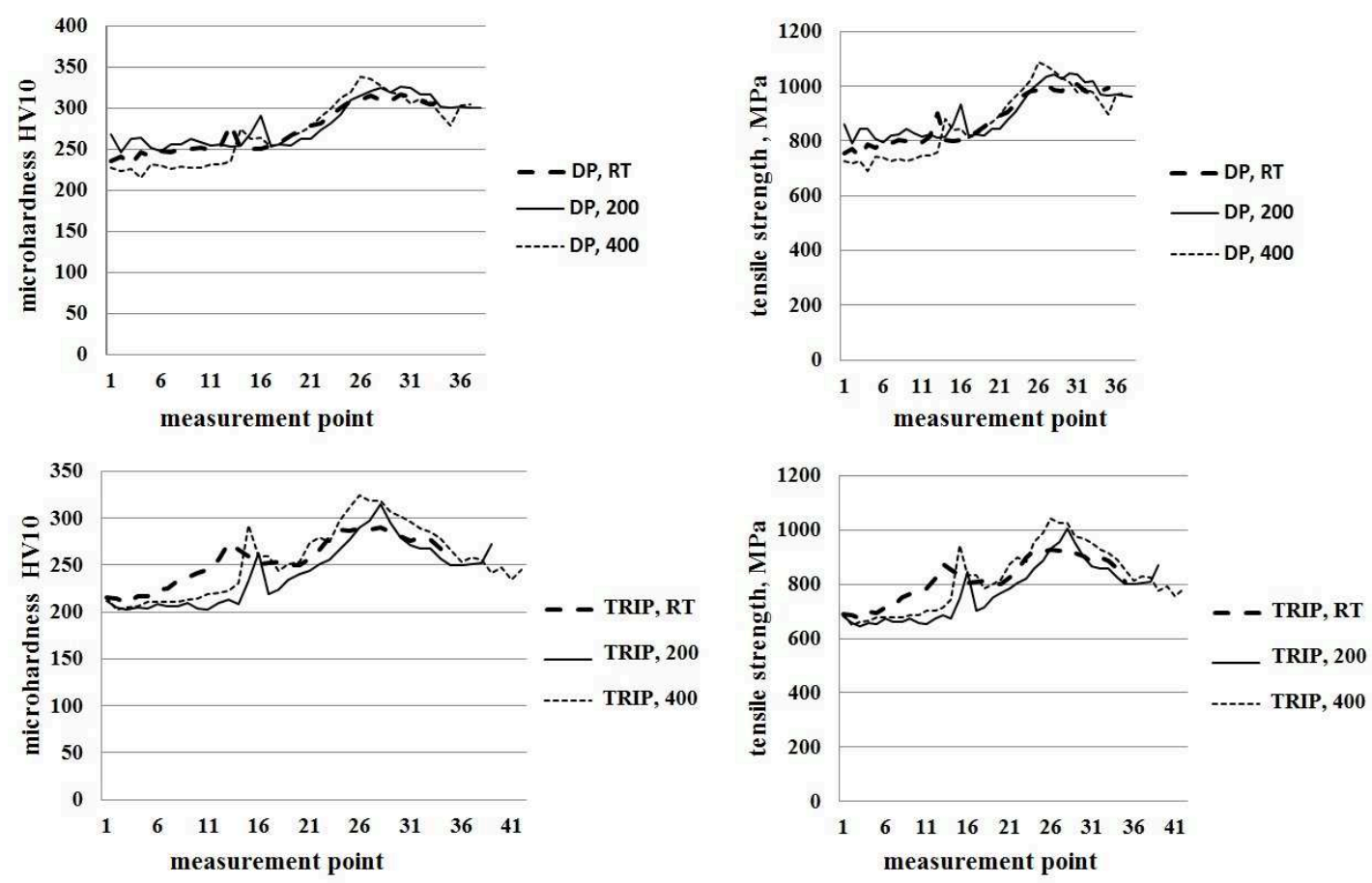

Fig. 5. Microhardness and tensile strength change for specimen after punch stretch test

\section{Summary}

Based on this study, the following conclusions can be made:

- warm forming is a complex process for advanced high strength steels,

- the thermal and mechanical stability of martensite and retained austenite should be considered in forming at elevated temperature,

- strain hardening capacity decreases for a given TRIP690 steel which results in neck occurrence (local thinning) at a temperature of $200{ }^{\circ} \mathrm{C}$ it means that the strain distribution is more uniform in cold forming (because of TRIP effect) than in warm forming,

- the retained austenite stability is responsible for the austenite-to-martensite transformation rate, and as a result, for the steel's ability to delay necking,

- there was no necking formation for DP steel at $200^{\circ} \mathrm{C}$, it means that this temperature has no noticeable influence on formability,

- temper (blue) embrittlement occurred for both investigated steels at temperature $400{ }^{\circ} \mathrm{C}$.

The attributes of TRIP-assisted steels can be beneficial for warm forming in relation to the enhanced stability of austenite against straining at elevated temperatures - more austenite phase can exist in the final part which increases energy absorption by TRIP effect in the event of a car crash. However, the tempering should be avoided within the critical temperature range due to temper brittleness. The retained austenite stability is a complex issue and it is influenced by many parameters and factors occurring in sheet metal forming, so the warm forming should be carefully evaluated for particular steel and for certain part implementation. 


\section{References}

[1] J.A. Rodriguez-Martinez, R.Pesci, A.Arias, R.Zaera, D.A. Pedroche, Thermo-mechanical behaviour of TRIP 1000 steel sheets subjected to low velocity perforation by conical projectiles at different temperatures

[2] T. Nishibata, Camp-ISIJ, 21, 2008: 597

[3] Liu D et al. ISIJ International, 43(3), 2003: 433

[4] Y Nagataki, Tsuyama S, Hosoya Y, Okita T, Proc. Symp. Of High Strength Steels for Automotive, 1994: 239

[5] H. Mohrbacher, NiobelCon bvba, Schilde, Belgium, Metallurgical optimization of martensitic steel sheet for automotive applications

[6] R.M. Horn, Robert O. Ritchie, Mechanisms of tempered martensite embrittlement in low alloy steels

[7] R. Krupa, Warm sheet metal forming of Advanced High Strength Steel- process investigation and comparison to cold forming, International Conference on Advanced Metal Forming Processes in Automotive Industry AutoMetForm2014

[8] V. Ploshikhin, A. Prihodovsky, J. Kaiser, R. Bisping, H. Lindner, C. Lengsdorf, K. Roll, New heating technology for the furnace-free press hardening process 